\title{
CAN WE PREDICT MAXILLARY SINUS MUCOSA PERFORATION?
}

\author{
Samer Kasabah, Jiř́i Krug, Antonín Šimůnek, Miguel Cevallos Lecaro
}

University Hospital in Hradec Králové: Department of Dentistry, Center of Dental Implantology

Summary: This study was carried out to evaluate the prevalence of sinus mucosa perforation occurred during maxillary sinus mucosa elevation surgery, its relation to objective conditions and to the causative medical history, and its influence on postoperative sinusitis, as well. One hundred and forty-six sinus lift procedures have been evaluated in 118 patients. The prevalence of the sinus mucosa perforation was evaluated and subdivided into four groups according to its size and way of treatment. No relation was observed between the perforation and the presence of sinus septa, smoking, radiographic thickening and cyst-like lesions of the maxillary sinus, and previous sinus allergy $(\mathrm{P}<0.05)$. Despite of high prevalence of the perforation of the mucosa $(56.16 \%)$, no signs of bone graft infection or maxillary sinusitis were noted in any of our patient.

Key words: Maxillary sinus; Mucosa perforation; Sinus lift

\section{Introduction}

The aim of the dental implantology is to make implant treatment possible to all patients who may benefit from it. The advanced bone loss and the spongy bone available in the posterior upper jaw pose serious challenges for implant therapy. Recently, the maxillary sinus floor elevation (sinus lift operation) has opened up a new way of placing endosseous implants despite marked bone lack $(4,43)$. One of the most complications during the procedure is sinus mucosa perforation (SMP) $(30,37)$. It is generally agreed that every effort should be made to minimize SMP. However, this is not always possible, because the sinus mucosa is extremely thin, friable, and easily perforated (20). SMP can cause loss of graft material within the sinus that can lead to a sinusitis $(3,17,25,26,35,41)$. Furthermore, a greater bacterial penetration into the graft material through the torn mucosa, and risks of graft contamination can be increased (17). To our knowledge, SMP have not been separately investigated yet.

\section{Materials and methods}

All patients who demanded sinus augmentation and endosseous implants were included in this study (118 patients, 58 men and 60 women). The age was ranging from 29 to 58 years with mean of 42 years. Each patient was either partially edentulous in a posterior maxilla quadrant requiring fixed restoration or was totally edentulous indicating fixed removable prosthesis. The medical history including smoking and maxillary pathology-related symptoms was recorded. Patients with a recent history of acute maxillary sinusitis were excluded. Patient was considered a smoker if the patient smokes at least one cigarette daily for more than six months continuously. Preoperative planning consisted of clinical examination of the upper alveolar crest and radiographic assessment with panoramic radiographs. Water's projection or computer tomographies were used when required. This radiographic survey was also used to identify possible maxillary sinus septa. All patients received appropriate antibiotics that were started 24 hours preoperatively and continued for one week.

One hundred and forty-six sinus lift procedures were carried out as described by Boyne and James (4). Once SMP was identified, the sinus elevation procedure was modified and the SMP management was performed depending on the perforation size (Fig. 1, 2). The mucosa was elevated around the perforation, not to enlarge its size and then covered using a small piece of hemostat absorbable fabric (Surgicel ${ }^{\circledR}$, Ethicon, Johnson\&Johnson) to prevent migration of materials into the sinus cavity (Fig. 3). When the SMP was sealed (negative nose-blowing test), the procedure was completed in routine fashion (Fig. 4). We registered the prevalence and the size of SMP. The operated sinuses were comprised into three groups: Group A no perforation occurred during the operation (64 sinuses), in Group B small perforations $(<2 \mathrm{~mm}$ diameter) were registered without need of treatment (15 sinuses), and Group C (66 sinuses) included sinuses with all perforation covered by Surgicel ${ }^{\circledR}$. When SMP was very large and we could not close it, the procedure was abandoned and it could be tried again after a minimum six weeks. It was standard to perform the Valsalv's maneuver in all of our operations to confirm the absence or the sufficient treatment of 


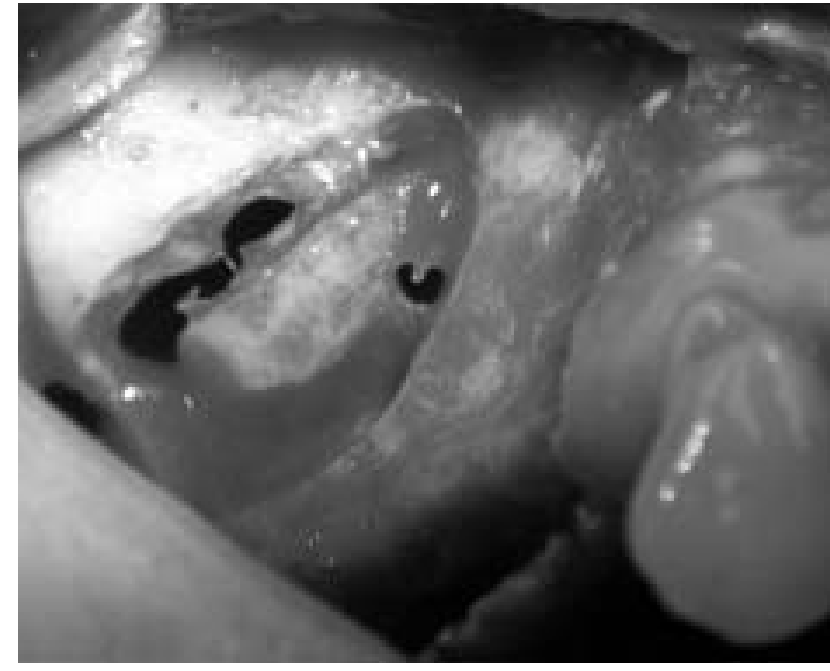

Fig. 1: SMP occurred during the lateral wall osteotomy.

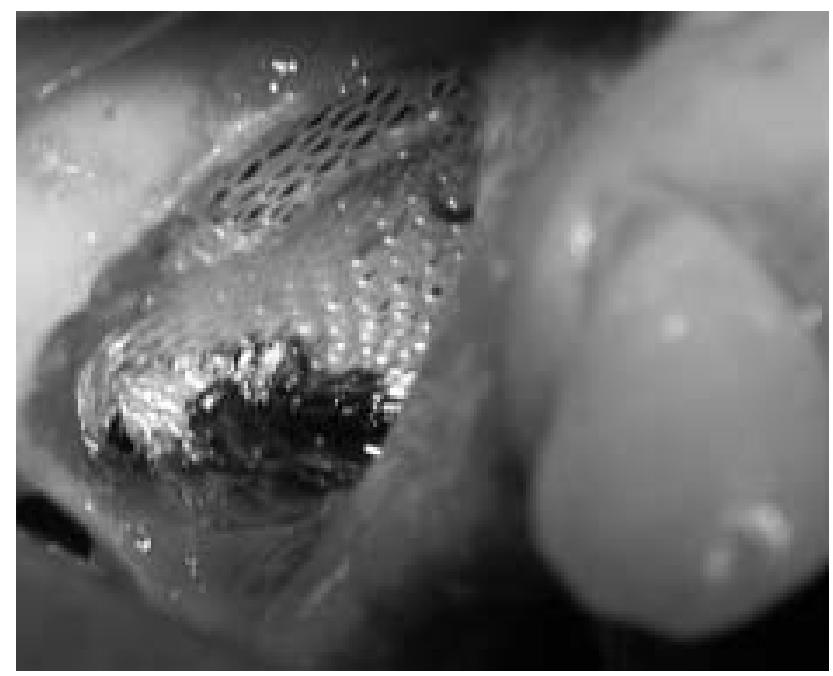

Fig. 3: The mucosa elevation was performed carefully around the SMP and then it was covered with Surgicel ${ }^{\circledR}$.

the SMP. We used following augmentation materials: $\beta$-tricalcium phosphate ceramic $\left(\right.$ Cerasorb $^{\circledR}$, Curasan-Pharma, Kleinostheim, Germany), deproteinized cancellous bovine bone (Bio-Oss ${ }^{\circledR}$, Geistlich, Wolhusen, Switzerland), and natural red alga (Algipore ${ }^{\circledR}$, Friadent, Mannheim, Germany). These materials were mixed with the patient's intravenous blood and used alone or in combination with autograft harvested from maxillary tuberosity. Our decision concerning the simultaneous implant placement was not changed if the SMP was properly managed. The patients were called for clinical and radiographic check-ups and asked especially about sinus related pathology (e.g. infection of the maxillary sinus, loss of bone particles through the nose, etc.).

The aim of this study was to evaluate the prevalence of SMP being occurred during the sinus lift procedure, its relation to the objective conditions and causative medical

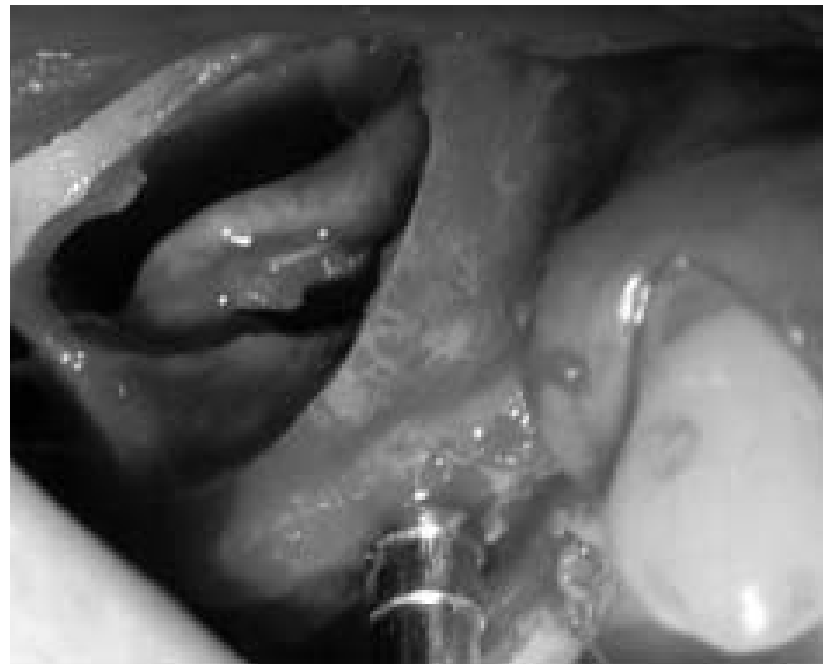

Fig. 2: SMP became larger during mucosa dissection.

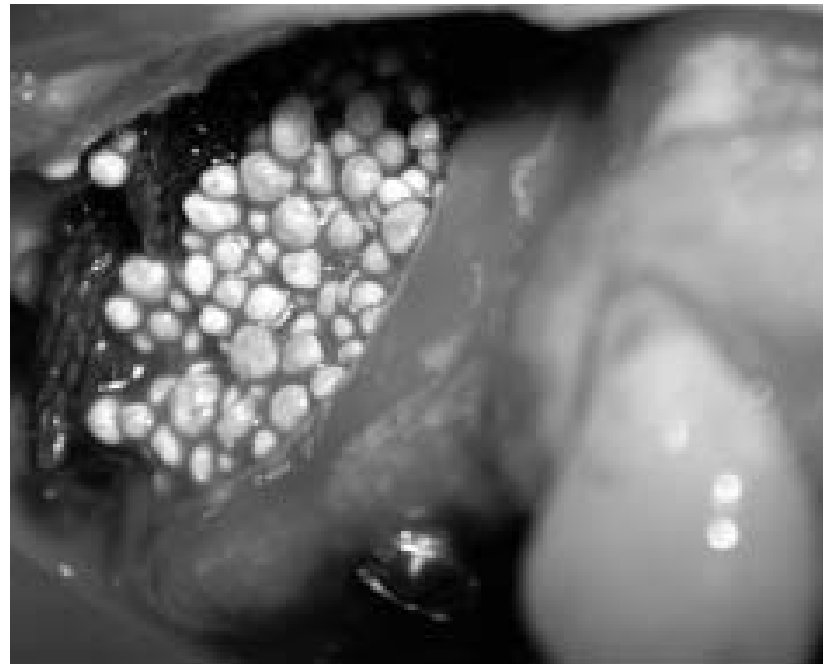

Fig. 4: Once the SMP is sealed, the procedure was completed in routine fashion.

history, and its influence on postoperative sinusitis. The correlation between these conditions and SMP was evaluated statistically using the Fisher's exact test.

\section{Results}

Sinus mucosa perforation occurred in 82 of our 146 operations (56.16\%). Table (1) and figure (5) demonstrate SMP size, number, prevalence, and its treatment. The lowest prevalence of SMP was observed in radiographically evident thickening of the sinus mucosa (30\%) (Tab. 2). The prevalence of SMP in radiographically visible cyst-like sinus lesions was $100 \%$ (Tab. 2).

Using Fisher's exact test $(\mathrm{P}<0.05)$, we did not find any correlations between SMP and all of the above-mentioned findings $(P=0.101)$ and $(P=0.259)$, respectively. 

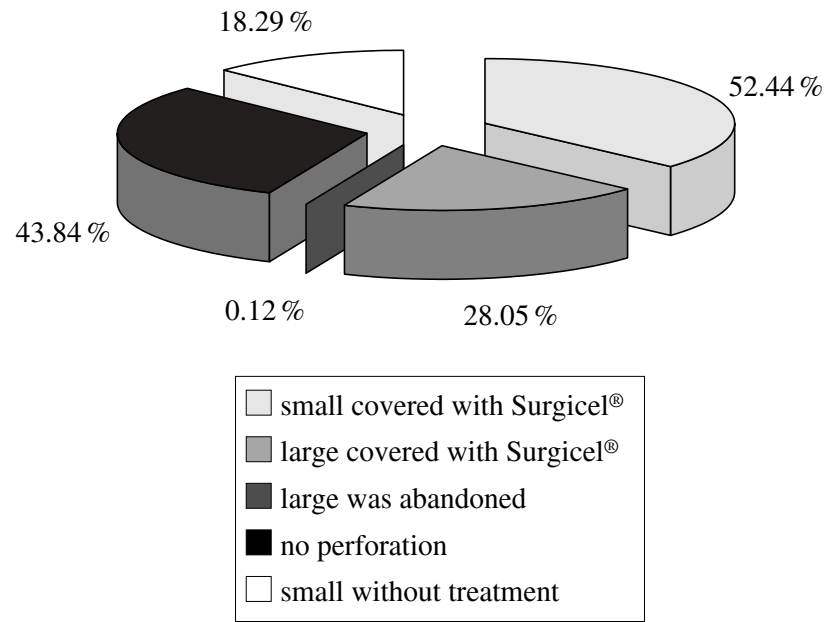

Fig. 5: SMP percentage and its treatment.

Tab. 1: The number and treatment of SMP.

\begin{tabular}{|l|c|l|}
\hline \multicolumn{3}{|c|}{ Sinus mucosa perforation $(\mathrm{SMP})(\mathrm{n}=82)$} \\
\hline Size & Number & Treatment \\
\hline Small $(<2 \mathrm{~mm})$ & 15 & without treatment \\
\hline Small $(<2 \mathrm{~mm})$ & 43 & covered with Surgicel $^{\circledR}$ \\
\hline large $(>2 \mathrm{~mm})$ & 23 & covered with Surgicel $^{\circledR}$ \\
\hline large $(>2 \mathrm{~mm})$ & 1 & abandoned \\
\hline
\end{tabular}

Some relationship, we figured out in the presence of sinus septa $(P=0.058)$, but statistically the correlation was not significant.

No relationship was registered in smoking patients $(\mathrm{P}=$ $1.000)$ and in patients with allergic anamnesis $(P=1.000)$. No relation was found between SMP and smoking patients with sinus septa $(\mathrm{P}=0.177)$.

Despite of high prevalence of SMP, no signs of bone graft infection or maxillary sinusitis were noted in any patient.

\section{Discussion}

The present study did not confirm the relation between SMP and the objective conditions as well as the causative medical history related to sinus as was mentioned by some authors $(2,18)$. We recognized the SMP in $56,16 \%$ of our operations. The prevalence of the SMP in this study was very high in comparison with most other authors. Their re- sults ranged individually from $0 \%$ up to $58 \%$ ( $0 \%$ Peleg (22), 11 \% Leonardis (13), 14 \% Loukota, (15), 17 \% Wannfors (39), $20 \%$ van den Bergh (37), $30 \%$ Hallman (6), $34 \%$ Timmenga (32), $36 \%$ Raghoebar (26), $40 \%$ Mazor (16), and $16 \%$ to $58 \%$ Krennmair (12). However, these authors did not explain if they published all or only the treated SMP.

It has been mentioned that because the mucosa is strongly adherent to the sinus septa, the elevation of the mucosa without SMP is considered being almost impossible $(2,9)$. In our results, we did not confirm this experience, which can be explained as a consequence of more careful operation technique when the presence of sinus septa was expected. Cigarette smoking is considered as a pathophysiologic parameter that was found to be deleterious to the sinus graft $(21,42)$. We did not notice higher percentage of SMP among smokers. Therefore, smoking can be judged as the pathophysiologic risk factor for the graft success but not for SMP. According to our results, the radiographic thickening of the sinus mucosa, usually indicating chronic sinusitis, allergy etc., did not increase the prevalence of the SMP. Furthermore, it facilitated mucosa elevation. As well as, the radiographic cyst-like lesions of the maxillary sinus did not predispose the patients to a higher SMP percentage. Anyway, it is recommended to treat it before the sinus procedure to avoid graft infection.

Many authors $(7,40,41)$ proved by endoscopic examination the migration of augmentation material particles through the sinus mucosa. From our point of view, there are clinically observed and unobserved SMP. The latter may occur during application of the augmentation materials due to sharp edges of some of them. Many materials have been suggested to cover the perforation (resorbable cellulose membrane, collagen, cortical bone partition, demineralized laminar bone membrane) or it can be glued together with a fibrin sealant $(16,27,28,31,36,37)$. In addition, it is recommended to use a block graft rather than particulated grafts, when perforation is larger than $5 \mathrm{~mm}(10,31)$. Pikos (24) described the technique of closure of the SMP using resorbable suture. From our experience Surgicel ${ }^{\circledR}$ is a cheap, satisfactory material for closing of different SMP sizes.

It was surprising that despite of high prevalence of SMP, we registered no sinusitis during our study. Timmenga et al. (32) reported that two sinuses from 85 sinuses developed subacute maxillary sinusitis and in one of these patients the sinus mucosa had been perforated accidentally during the surgical procedure. However, probably some

Tab. 2: Observation results.

\begin{tabular}{|l|c|c|c|c|c|c|}
\hline & $\begin{array}{c}\text { Sinus } \\
\text { septa }\end{array}$ & $\begin{array}{c}\text { Cyst-like } \\
\text { lesions }\end{array}$ & $\begin{array}{c}\text { Mucosa } \\
\text { thickness }\end{array}$ & Smoking & Allergy & $\begin{array}{c}\text { Smoking } \\
\text { and septa }\end{array}$ \\
\hline The number of the cases & 16 & 3 & 10 & 23 & 6 & 3 \\
\hline Perforation occurrence & 13 & 3 & 3 & 13 & 3 & 2 \\
\hline Percentage & $81.25 \%$ & $100 \%$ & $30 \%$ & $56.5 \%$ & $50 \%$ & $66.7 \%$ \\
\hline
\end{tabular}


transient sinusitis, as Perko (23) mentioned, might happen in a number of our patients, but was not enough obvious to differentiate it from postsurgical symptoms.

There are different ways how to keep the graft mixture in solidified mass and to prevent graft particle migration. Hallman et al (6) added fibrin glue (Tisseel ${ }^{\circledR}$, Duo Quick Immuno, Vienna, Austria) to graft material to make it easier to handle and to hinder particles from migration in case of SMP. Patient's blood, as we noticed, can act in a similar way as tissue glue in discouraging particle extravasations.

The following rules were essential in all our operations. First, any hole in the mucosa should be closed. When SMP was small, there was no need for further measures because the epithelial lining "falls together" when lifting the door so there is not a great chance of losing graft material into the sinus (37). Second, the sinus mucosa should be completely elevated before graft placement. According to the grafthealing hypothesis in the sinus, mentioned by several authors, the bone formation in an augmented maxillary sinus originates from the floor and the lateral walls and the mucosa does not possess any osteogenetic potential $(1,4,7,8,38)$. That means if there is any unelevated mucosa between the augmentation material and the osseous bed, consolidation will not occur. At the same time the graft will not be secure enough for the placement of osseointegrated implants and predisposes to infection or failure (5). Postoperative maxillary cysts following maxillary sinus elevation were reported. On the histologic examination, their membrane consisted of sclerous sinus mucosa lined with respiratory ciliated epithelium $(14,19)$.

It is known from some authors' observation that less bone formation is depicted close to sinus mucosa $(8,18)$. The sinus mucosa does not have apparent osteogenic potential and its contribution as an angioblast-osteoblast source and/or as endoperiosteum is just becoming understood, but it is probably secondary in importance in sinus graft healing (29). Therefore, the most important task for the mucosa, during sinus grafting, is to act as a net for the graft material.

More than one type of management have been reported how to reduce SMP prevalence. Kent et al. suggested leaving very thin part of sinus wall above the mucosa during osteotomy preparation to avoid SMP with the rotatory instrument. However, the operator must use excessive force to infracture the rest wall of the sinus cavity and this may result in a large tear in the sinus mucosa (11). Ziccardi recommended the use of a diamond bur in contrast to a fluted bur, because it tends to displace the mucosa rather than grab and tear it. Torrella et al. described technique when the sinusal fenestration osteotomy was made by ultrasound technique, which reduced the risk of SMP and improved the quality of the osteotomy (33).

\section{Conclusion}

The authors concluded that no relations were noted between SMP and the preoperative condition (sinus septa, smoking, radiographic thickening of the mucosa, radiographic cyst-like lesions of the sinus, and sinus previous allergy). SMP can be problematic but if it is appropriately managed, it does not harm the healing process of the bone graft and could hardly be connected with the development of postoperative sinusitis. On the other hand, it would be convenient to analyze larger number of patients to confirm the relation between SMP and preoperative conditions.

\section{Acknowledgements}

The authors would like to thank doc. MUDr. Věra Hubková, CSc. and doc. MUDr. Radovan Slezak, CSc. for their valuable advice and help in reviewing this manuscript.

\section{References}

1. Avera SP, Stampley WA, McAllister BS. Histologic and clinic observation of resorbable and non-resorbable barrier membrane used in maxillary sinus graft containment. Int J Oral Maxillofac Implants 1997;12:88-94.

2. Betts NJ, Miloro M. Modification of the sinus lift procedure for septa in the maxillary antrum. Int J Oral Maxillofac Surg 1994:52:332-3.

3. Block MS, Kent JN. Maxillary sinus grafting for totally and partially edentulous patients. J Am Dent Assoc 1993;124:139-43.

4. Boyne PJ, James RA. Grafting of the maxillary sinus floor with autogenous marrow and bone. Int J Oral Maxillofac Surg 1980;38:613-7.

5. Brown $\mathrm{CW}$, Orme TJ, Richardson HD. The rate of pseudarthrosis (surgical union) in patients who are smokers and patients who are nonsmokers: A comparison study. Spine 1986;11:942-3.

6. Hallman Mats, Cederlund A, Lindskog S, Lundegren S, Sennerby L. A clinical histologic study of bovine hydroxyapatite in combination with autogenous bone and fibrin glue for maxillary sinus floor augmentation. Results after 6 to 8 months of healing. Clin Oral Impl Res 2001;12:135-43.

7. Hüzreler MB, Quińones CR, Kirsch P, Strub JR, Caffess RG. Maxillary sinus aug mentation using different grafting materials and dental implant in monkeys. Part III. Evaluation of autogenous bone combined with porous hydroxyapatite. Clin Oral Impl Res 1997;8:476-86.

8. Jensen OT: Treatment planning for sinus grafts. In: Jensen OT (ed): The Sinus Bone Graft. Chicago: Quintessence, 1998; Chapter 5: 49-68.

9. Jensen OT, Greer RO. Immediate placement of osseointegrated implants into the maxillary sinus augmented with mineralized cancellous allograft and Gore-Tex: second-stag surgical and histological findings. In: Laney WR, Tolman DE (eds): Tissue integration in Oral, Orthopedic and Maxillofac Reconstruction, Chicago: Quintessence, 1992:321-33.

10. Keller EE, Ecker SE, Tolman DE. Maxillary antral and nasal one-stage inlay composite bone graft: Preliminary report on 30 recipient sites. Int J Oral Maxillofac Surg 1994;52:438-47.

11. Kent JN, Block MS. Simultaneous maxillary sinus floor bone grafting and placement of hydroxyapatite coated implants. Int J Oral Maxillofac Surg 1989;47: $238-42$.

12. Krennmair G, Ulm C, Lugmayr H. Maxillary sinus septa: incidence, morphology and clinical implications. Int J Cranio Maxillofac Surg 1997;25:261-5.

13. Leonardis D, Pecora GE. Prospective study on the augmentation of the maxillary sinus with calcium sulfate: Histological results. J Periodontol 2000;71(6): $940-7$

14. Lockhart R, Ceccaldi J, Bertrand JC. Postoperative maxillary cyst following sinus bone graft: Report of a Case. Int J Oral Maxillofac Implants 2000;15:583-6.

15. Loukota RA, Isakson SG, Linner ELJ, Blomqvist JE. A technique for inserting endosseous implants in the atrophic maxilla in a single stage procedure. British J Oral Maxillofac surgery 1992;30:46-9.

16. Mazor Z, Peleg M, Gross M. Sinus augmentation for single-tooth replacement in the posterior maxilla: A 3-year follow-up clinical report. Int J Oral Maxillofac Implants 1999:14:55-60.

17. Misch CE. Maxillary sinus augmentation for endosteal implants: organized alternative treatment plans. International. J Oral Implantol 1987;4:49-58

18. Misch CE. The maxillary sinus lift and sinus graft surgery In: Misch CE. Contemporary implant dentistry. Mobsy, 1998: Chapter 30.

19. Misch CM, Misch CE, Resnik RR et al. Postoperative maxillary cyst associated with sinus elevation procedure: a case report. J Oral Implant 1991;18:432-7.

20. Momtaheni D, Schweitzer K, Muenchinger F. Technique for stabilization of autogenous cancellous bone grafts in sinus lift procedures. Oral Surg Oral Med Oral Path 1994;78:14-6.

21. Mosely LH, Finseth F, Goody M. Nicotine and its effects on wound healing. J Plast Reconstr Surg 1978;61:570-6. 
22. Peleg M, Mazor Z, Chaushu G, Garg AK. Sinus floor augmentation with simultaneous implants placement in the severely atrophic maxilla. J Periodontol 1998;2:1397-403.

23. Perko M. Maxillary sinus and surgical movement of the maxilla. J Oral Surg 1972;1:177.

24. Pikos MA. Maxillary Sinus Membrane Repair: Report of a Technique for large Perforations. Implant Dent 1999;8:29-34.

25. Quiney R, Brimble E, Hodge M. Maxillary sinusitis from dental osseointegrated implants. J Laryngol Otol 1970;104:333.

26. Raghoebar GM, Brouwer TJ, Reintsema H, Van Ort RP. Augmentation of maxillary sinus floor with autogenous bone for placement of endosseous implants: A preliminary report. Int J Oral Maxillofac Surg 1993;51:1198-1203.

27. Small SA, Zinner I D, Panno FV, Shapiro HJ, Stein JI. Augmenting the maxillary sinus for implants: Report of 27 patients. Int J Oral Maxillofac Implant 1993;8:523-8.

28. Sullivan SM, Bulard RA, Meaders R, Patterson MK. The uses of fibrin adhesive in sinus lift procedures. Oral Surg Med Pathol Radiol Endod 1997;84;616-9.

29. Summers RB. The osteotome technique: Part 4-Future site development. Compendium 1995;16:1091-4.

30. Ten Bruggenkate CM, van den Bergh JPA. Maxillary sinus floor elevation: a valuable pre-prosthetic procedure. Periodontology 2000 1999;17:176-82.

31. Tidwell JK, Blijdorp PA, Stoelinga PJW, Brouns JB, Hinderks F. Composite grafting of the maxillary sinus for placement of endosteal implants-a preliminary report of 48 patients. Int J Oral Maxillofac Surg 1992;21:204-9.

32. Timmenga NM, Raghoebar GM, Boering $G$ et al. Maxillary sinus function afte sinus lifts for the insertion of dental implants. Int J Oral Maxillofac Surg 1997;55 936-9.

33. Torrella F, Pitarch J, Cabanes G, Antiua E. Ultrasonic ostectomy for the surgica approach of the maxillar5y sinus: A technique note. Int J Oral Maxillofac Implants 1998;13:697-700.

34. Triplett RG, Schow SR. Autogenous bone grafts and endosseous implants: Complementary techniques. Int J Oral Maxillofac Surg 1996;54:486-94.

35. Ueda M, Toshio K: Maxillary sinusitis caused by be dental implants; Report of two cases. Int J Oral Maxillofac Surg 1992:50:285-7.

36. Valentini P, Abensur D. Maxillary sinus floor elevation for implant placement with demineralized freeze-dried bone and bovine bone (Bio-Oss): A clinical study of 20 patients. Int J Periodontics Restor Dent 1997;17(3):233-41.

37. Van den Bergh JPA, ten Bruggenkate CN, Disch FJM, Tuinzing DB. Anatomical aspects of sinus floor elevations. Clin Oral Impl Res 2000;11:256-65

38. Vlassis JM, Hurzeler MB, Quinones CR. Sinus lift augmentation to facilitate placement of non submerged implants-a clinical and histological report. Pract Perio Aesthet Dent 1993:5(2):15-23.

39. Wannfors K, Johansson B, Hallman M, Strandkvist T. A prospective randomized study of 1 - and 2-stage sinus inlay bone grafts: 1-year follow-up. Int J Oral Maxillofac Implants 2000;15:625-32.

40. Wetzel AC, Stich H, Caffesse RG. Bone apposition onto oral implant via guided tissue regeneration. A pilot study. Clin Oral Implants Res 1995;6(3):164-72.

41. Wiltfang J, Merten HA, Becker HJ. Klinische, röntgenologische und sinuskopische Nachkontrolle nach Sinusbodenelevation. Z Zahnärzt Implanto 1996;12:80-4.

42. Wittbjer J, Palmer B, Robbin $\mathrm{M}$ et al. Osteogenic activity in composite grafts of demineralized bone and marrow. Chicago: Orthop 1983;173:229.

43. Wood RM, Moore DL. Grafting of the maxillary sinus with intraorally harvested autogenous bone prior to implant placement. Int J Oral Maxillofac Implants 1988;3:209-14

Submitted October 2002.

Accepted December 2002.

Samer Kasabah, DDS,

University Hospital in Hradec Králové,

Department of Dentistry,

Center of Dental Implantology, 50005 Hradec Králové,

Czech Republic.

e-mail: skasabah@hotmail.com 